\title{
FAKTOR PENENTU ALIH KODE DALAM TRANSAKSI JUAL BELI DI PASAR TUMBANG SAMBA KATINGAN TENGAH KALTENG
}

\author{
Lili Agustina dan Johan Arifin \\ Pendidikan Bahasa dan Sastra Indonesia \\ STKIP PGRI Banjarmasin \\ Jalan Sultan Adam, Komplek H. Iyus, No. 18 RT.23 Banjarmasin, \\ Kalimantan Selatan. Kode pos 70121 \\ email: lili.agustina@stkipbjm.ac.id
}

\begin{abstract}
Abstrak
Penelitian yang berjudul Faktor Penentu Alih Kode dalam Transaksi Jual Beli di Pasar Tumbang Samba Katingan Tengah Kalteng bertujuan untuk melakukan analisis data faktor-faktor penentu yang mempengaruhi alih kode yang dilakukan antara penjual dan pembeli dengan mengaitkan kondisi ilmiah.

Pendekatan yang digunakan dalam penelitian ini adalah pendekatan kualitatif dengan metode deskriptif. Ada dua jenis data dalam penelitian ini yakni (1) tuturan yang berisi realisasi variasi bahasa yang digunakan oleh penjual dan pembeli dalam melakukan transaksi jual beli dan (2) berupa catatan deskriptif. Catatan deskriptif memberi gambaran tentang faktor penentu terjadinya alih kode yang terjadi antara penjual dan pembeli. Teknik pengumpulan data yang digunakan dalam penelitian ini, yakni pengamatan langsung, wawancara, teknik penyimakan yakni teknik simak bebas libat cakap, selain itu juga teknik rekam dan teknik catat di lapangan.

Beragamnya bahasa yang digunakan dalam dalam proses transaksi jual beli di Pasar Banjar Kecamatan Katingan Kabupaten Katingan Kalteng ini sehingga menimbulkan terjadinya alih kode. Faktor penentu terjadinya alih kode dalam transaksi jual beli di Pasar Tumbang Samba Katingan Tengah Kalteng, yaitu (a) pembeli dan penjual sudah saling kenal, (b) menyesuaikan dengan bahasa pembeli, (c) agar mendapatkan harga murah, (d) adanya orang ketiga, (e) adanya pembeli lain, (f) pembeli terkejut dengan harga yang ditawarkan, (g) penjual ingin berpura-pura kepada pembeli, (h) perasaan jengkel penjual kepada pembeli, dan (i) penjual ingin menekankan.
\end{abstract}

Kata kunci: alih kode, jual beli, pasar

\section{Pendahuluan}

Manusia sebagai makhluk sosial senantiasa berinteraksi dengan sesamanya dengan menggunakan bahasa. Bahasa mempunyai suatu peran yang sangat mendasar yang tidak mungkin terpisahkan oleh masyarakat pemakainnya. Fungsi mendasar dari bahasa adalah untuk mengaktualisasikan hubungan timbal balik di dalam masyarakat, baik secara perorangan maupun berkelompok.

Bentuk dan tuturan yang terjadi di pasar, yaitu tempat transaksi jual beli sangatlah beragam. Hal ini dimaksudkan agar penutur (penjual) maupun lawan tutur (pembeli) dapat saling mengerti dan memahami apa yang dimaksudkan antara kedua belah pihak tersebut. Keanekaragaman pengunaan bahasa, antara penjual dan pembeli akan jelas tampak pada saat penjual dan pembeli melakukan interaksi atau berkomunikasi. Bahasa-bahasa tersebut mereka gunakan saat berinteraksi dengan memperhatikan situasi dan kondisi tertentu. 
Masyarakat itu terdiri dari individu-individu. Masyarakat secara keseluruhan dan individu saling mempengaruhi dan saling ketergantungan. Bahasa sebagai milik masyarakat juga tersimpan dalam diri masing-masing individu. Menurut Chaer (2003: 66) dalam masyarakat yang bilingual atau multilingual sebagai akibat adanya kontak bahasa (dan kontak budaya), sering kali terjadi peristiwa atau kasus yang disebut inteferensi, integrasi, alih kode (code switching), dan campur kode (code mixing). Keempat peristiwa ini gejalanya sama, yaitu adanya unsur bahasa lain dalam bahasa yang digunakan, tetapi konsep masalahnya tidak sama.

Alih kode sebagai pengggunaan variasi bahasa lain atau bahasa lain, misalnya bahasa satu dengan bahasa yang lain untuk menyesuaikan diri atau menyesuaikan bahasanya pada saat berkomunikasi dengan lawan tutur dengan memperhatikan peran atau situasi lain atau karena adanya partisipan lain, sedangkan campur kode adalah campuran bahasa yang satu dengan bahasa yang lain pada saat berkomunikasi atau penggunaan satuan bahasa dari satu bahasa ke bahasa lain untuk memperluas gaya bahasa atau ragam bahasa.

Alih kode yang terjadi di Pasar Tumbang Samba Kecamatan Katingan Tengah Kabupaten Katingan dipilih untuk objek penelitian karena banyak masyarakat yang bilingual dan ada juga yang multilingual. Penjual dan pembeli memiliki bahasa yang beragam sehingga proses transaksi jual beli yang terjadi menggunakan bahasa sebagai alat komunikasi yang bervariasi. Ada beberapa bahasa yang digunakan oleh masyarakat di Kecamatan Katingan Tengah Kabupaten Katingan, yaitu Bahasa Banjar (BB), Bahasa Katingan (BK), Bahasa Jawa (BJw) dan Bahasa Indonesia (BI). Bahasa Banjar (BB) dan Bahasa Katingan (BK) yang sering digunakan dalam berinteraksi dan berkomunikasi yang juga dipakai oleh semua kelompok etnis di Pasar Kecamatan Katingan Tengah.

\section{Metode}

Pendekatan yang digunakan dalampenelitianiniadalah pendekatan kualitatif. Hal ini karena pendekatan kualitatif diharapkan mampu menghasilkan suatu uraian tentang ucapan, tulisan, dan perilaku yang dapat diamati/dilihat dari suatu individu, kelompok, dan masyarakat.

Penelitian ini bertujuan untuk mendeskripsikan fenomena dalam alih kode yang digunakan pada saat melakukakan transaksi jual beli di PasarTumbang Samba Kecamatan Katingan Tengah Kabupaten Katingan secara alamiah. Alamiah dalam penelitian ini, yakni fenomena yang menjadi sasaran penelitian ini tidak dibuat-buat, melainkan akan dideskripsikan sebagaimana adanya. Penelitian tentang alih kode dalam ranah transaksi jual beli di Pasar Tumbang Samba Kecamatan Katingan Tengah Kabupaten Katingan ini berkaitan dengan suatu gejala kebahasaan yang sifatnya alamiah. Data yang dikumpulkan berasal dari lingkungan yang nyata dan situasi apa adanya, yaitu 
dialog antara penjual dan pembeli. Hal ini disebabkan karena ada data yang terkumpul dianalisis dan dipaparkan secara deskriptif.

Secara teoritis, pendekatan yang digunakan dalam penelitian ini adalah pendekatan sosiolinguistik yakni pendekatan penelitian ilmu bahasa dalam kaitannya dengan penggunaan bahasa masyarakat.

Peneliti berperan sebagai instrumen utama. Peneliti bertindak secara aktif mendeskripsikan, menganalisis dan menyimpulkan data. Peneliti dalam hal ini sebagai instrumen utama karena memegang kendali dalam proses pengumpulan data, pendeskripsikan data, penganalisis data, serta penarik simpulan dari hasil penelitian.

Penelitian ini merupakan penelitian lapangan sehingga lokasi penelitian pun dilakukan di lapangan. Adapun penelitian ini akan dilakukan di Pasar Tumbang Samba Kecamatan Katingan Tengan Kabupaten Katingan Kalimantan Tengah untuk mengambil data yang diperlukan.

Ada dua jenis data dalam penelitian ini, yakni (1) tuturan yang berisi realisasi variasi bahasa yang digunakan oleh penjual dan pembeli dalam melakukan transaksi jual beli yang di dalamya terdapat alih kode, dan (2) berupa catatan deskriptif. Catatan deskriptif memberi gambaran tentang alih kode yang terjadi antara penjual dan pembeli.

Tahapan dalam pengumpulan data dalam penelitian ini didasarkan pada prosedur berikut ini: 1. Pengumpulan data. Data yang digunakan dalam penelitian ini adalah data dari hasil rekaman dan catatan yang dilakukan.

2. Pentranskripsian data rekaman ke dalam bentuk tulisan melalui penyesuaian tulisan dengan menggunakanPedomanUmumEjaan Bahasa Indonesia (PUEBI).

3. Pengidentifikasian data yang termasuk faktormenyebabkanalih kode.

\section{Hasil dan Pembahasan}

Dalam berbagai kepustakaan linguistik, secara umum penyebab alih kode itu disebutkan antara lain adalah (1) pembicara atau penutur, (2) pendengar atau lawan tutur, (3) perubahaan situasi dengan hadirnya orang ketiga, (4) perubahan dari formal ke informal atau sebaliknya, (5) perubahan topik pembicaraan, dan (6) faktor saling kenal dan saling akrab antarpenutur.

Berdasarkan hasil penelitian di lapangan, yakni di Pasar Tumbang Samba Kecamatan Katingan Tengah diperoleh faktor penentu penjual dan pembeli melakukan alih kode.Dalam melakukan kegiatan transaksi jual beli di Pasar Banjar Tumbang Samba terdapat beberapa faktor yang mempengruhi penjual dan pembeli melakukan alih kode. Faktor-faktor tersebut sebagai berikut. 


\section{Pembeli dan Penjual Saling Kenal}

Peristiwa alih kode yang dilakukan oleh penjual dan pembeli bisa terjadi karena penjual dan pembeli sudah saling mengenal. Biasanya penjual maupun pembeli yang sudah saling mengenal atau akrab sering melakukan alih kode. Dalam proses tawar menawar, penjual bisa saja menawarkan dengan bahasa Banjar kemudian bisa beralih kode menjadi Bahasa Katingan (BK). Hal ini wajar saja karena Bahasa Katingan (BK) merupakan bahasa yang sering digunakan di Pasar Banjar Tumbang Samba Katingan Tengah. Bahasa yang digunakan pun bisa beragam sesuai dengan apa yang diinginkan mereka.
a. Peserta tutur
Pedagang ayam : jenis kelamin perempuan, umur 45 tahun, etnis Katingan
Pembeli : jenis kelamin perempuan, umur 42 tahun, etnis Banjar
b. Lokasi : Pasar Banjar Tumbang Samba Katingan Tengah
c. Topik : Tawar menawar ayam
Pembeli : Gasan siapa bacincang ayam 1
Buat siapa memotong ayam

Penjual : Gasan orang tadi. Ma Agus tukarakan nah ayam, sekilo haja Mama Agusai, nyaman dicincangakan. 2

Buat orang tadi. Ma Agus beli nah ayam, sekilo saja mama Agus, supaya dipotong

Pembeli

: Pire rega? 3 (BB-BK)

Penjual

Berara harganya?

Pembeli

: 35 ih, mili kah mama Agus. Jite piye tanau duwe kilo ije ons 4

35 saja. Beli kah mama Agus. Itu

Pembeli : Iyoh, pire rega hati manuk te nah. 5

Iya, berapa harga hati ayam itu.

Pada percakapan di atas penjual dan pembeli melakukan alih kode. Penjual sudah saling kenal dengan pembeli, yakni mama Agus. Hal ini dapat dilihat dari penggalan percakapan penjual kepada pembeli "Ma Agus tukarakan nah ayam, sekilo haja mama Agus ai, nyaman dicincangakan" (penggalan kalimat 2) yang maknanya adalah Bu Agus beli nah ayam, sekilo saja Ibu Agus, supaya dipotong ayamnya. Percakapan tersebut terlihat bahwa penjual sudah akrab dengan pembeli. Peneliti menemukan bahwa Ibu agus yang beretnis Banjar berkomunikasi menggunakan bahasa Katingan terhadap temannya, yakni penjual ayam yang beretnis Katingan. Pada awalnya penjual menggunakan bahasa Banjar untuk berkomunikasi kemudian dijawab oleh pembeli juga menggunakan bahasa Banjar. Pada penggalan kalimat 3 pembeli beralih kode menggunakan bahasa Katingan yaitu untuk menanyakan harga ayam yang berbunyi "Pire rega?" yang maknanya adalah 'Berapa harganya?' dan juga dijawab oleh pembeli menggunakan bahasa Katingan yang berbunyi “35 ih, mili kah mama Agus. Jite piye tanau duwe kilo ije ons" (penggalan kalimat 4) yang maknanya adalah '35 saja. Belikah Ibu Agus itu'. 


\section{Menyesuaikan dengan Bahasa Pembeli}

Alih kode yang juga sering dilakukan adalah disebabkan penjual berusaha menyesuaikan bahasa yang digunakan oleh pembeli. Agar komunikasi dalam transaksi jual beli dapat lancar diperlukan bahasa yang dapat dimengerti oleh kedua pembicara, yakni penjual dan pembeli. Di Pasar Banjar Tumbang Samba Kecamatan Katingan Kabupaten Katingan ini biasanya seseorang yang beretnis Jawa apakah itu penjual atau pembeli biasanya menggunakan bahasa Indonesia dalam berkomunikasi dengan orang lain. Etnis Jawa akan menggunakan bahasa Jawa apabila mereka sama-sama beretnis Jawa juga. Oleh sebab itu, mereka jarang menggunakan bahasa Jawa dalam proses transaksi jual beli di pasar Banjar. Berikut ini adalah percakapan yang menggambarkan peristiwa alih kode yang dilakukan penjual menyesuaikan dengan bahasa pembeli.
a. Peserta tutur
Pedagang sayur
Pembeli
b. Lokasi
c. Topik
Penjual
Pembeli
: Jenis kelamin perempuan, umur 33 tahun, etnis Jawa.
: Jenis kelamin perempuan, umur 49 tahun, etnis Banjar
Penjual
Pembeli
Penjual
: Pasar Banjar Tumbang Samba Katingan Tengah
: Tawar menawar sayur
: Sayur-sayur, Bu.1 (BI)
: Nukar waluh pang sabalah.2
Beli labu separoh.
: Sabalah jakah, sabigian yang ini 203 (BI-BB)
Separoh sajakah, sebiji yang ini 20.
: Sabalah haja gin, kena kada tamakan pulang kaya samalam
Separoh saja, nanti tidak termakan lagi seperti kemarin.
Pembeli
: Bujur jua, sabalah 10 ribu. Handak apa lagi?? 5
Benar juga, sebelah 10 ribu. Mau apa lagi?

Pada percakapan penjual dan pembeli pada saat membeli sayur, terlihar bahwa penjual melakukan alih kode. Pada mulanya penjual pada saat menawarkan sayur kepada pembeli menggunakan bahasa Indonesia yang berbunyi "Sayur-sayur, Bu” (penggalan kalimat 1). Ketika pembeli datang dan membeli sayur yakni labu dengan menggunakan bahasa Banjar, penjual pun beralih menggunakan bahasa Banjar yang berbunyi "Sabalah jakah, sabigian yang ini 20" yang maknanya adalah 'separoh sajakah, sebiji yang ini 20'. Jadi penjual berusaha menyesuaikan kode bahasa yang digunakan oleh pembeli, yaitu bahasa Banjar (pada penggalan kalimat 2,4,6) agar komunikasi yang terjalin dapat lancar dan adanya keakraban antara penjual maupun pembeli. Penutur sering melakukan alih kode untuk mengejar suatu kepentingan.

\section{Agar Mendapatkan Harga Murah}

Pada saat transaksi jual beli di Pasar Banjar Tumbang Samba Katingan Tengah sangat wajar apabila pembeli menginginkan membeli sesuatu/barang yang dibeli dengan harga murah dan penjual menginginkan untung yang banyak dari barang yang dijualnya. Keinginan penjual dan 
pembeli itu merupakan hal yang sudah biasa. Dalam transaksi jual beli, pembeli berusaha menawar harga barang yang dijual. Dalam proses menawar yang dilakukan pembeli tersebut supaya mendapatkan harga murah, tidak jarang pembeli menggunakan bahasa yang sama dengan penjual. Hal ini dapat dilihat bahwa pembeli yang beretnis Jawa yang juga mampu berbahasa Banjar ini dengan penjual yang beretnis Banjar.
a. Peserta tutur
Pedagang ikan : Jenis kelain perempuan, umur 40 tahun, etnis Banjar
Pembeli : Jenis kelamin perempuan, umur 37 tahun, etnis Jawa
b. Lokasi : Pasar Banjar Tumbang Samba
c. Topik
Penjual
: Tawar menawar ikan
: Iwak lais, iwak lais (menawarkan iwak lais kepada pembeli yang lewat) 1
Ikan lais ikan lais
Pembeli : Berapa satu kilo? (BI)2
Penjual : Sekilo 35 ribu. 3
Satu kilo 35
Pembeli $\quad: 30$ saja (BI) 4
Penjual : Kupadahakan hajalah wayah hini ngalih mancari iwak. 5
Kukatakan sajalah sekarang sulit mencari iwak
Pembeli : Kurangi pang nyaman aku tukari. 6 (BI-BB)
Penjual $\quad$ Kurangi supaya aku beli
Baiklah buat kamu 33 saja mengurangi 2 ribu.
Pembeli : Ayu ai bila kaya itu. 8

Baiklah bila seperti itu

Dalam percakapan di atas, terlihat bahwa pembeli melakukan alih kode dari semula menggunakan bahasa Indonesia kemudian beralih kode menggunakan bahasa Banjar. Agar mendapatkan harga murah, pembeli dapat menggunakan bahasa yang sama yang digunakan oleh penjual. Di sini tampak bahwa penjual merasa satu daerah sama pembeli.

Pada awal percakapan pembeli mengunakan Bahasa Indonesia (BI) untuk menanyakan berapa harga satu kilo ikan, yang kemudian beralih menggunakan Bahasa Banjar (BB). Percakapan pembeli menggunakan bahasa Banjar, yang berbunyi "Kurangi pang nyaman aku tukari" (penggalan kalimat 6) yang maknanya adalah 'Kurangi supaya aku beli.' Kemudian dijawab oleh penjual ikan yang menggunakan Bahasa Banjar (BB), yang berbunyi "Ayuja nah gasan kam 33 haja mangurangi 2 ribu" (penggalan kalimat 7) yang maknanya adalah 'Baiklah untuk kamu 33 saja mengurangi 2 ribu'. Karena pembeli menggunakan bahasa Banjar agar sama dengan bahasa yang dipakai penjual ikan dan juga dengan motif untuk mendapatkan harga murah, akhirnya penjual mengurangi harga ikan dari semula yang dirasa cukup mahal yakni 35 satu kilo menjadi 33 satu kilo. 
Vol.3 No.1, 1 April 2018

\section{Adanya Pembeli Lain}

Faktor yang mempengaruhi seseorang penjual melakukan alih kode dalam transaksi jual beli di Pasar Banjar Tumbang Samba Kecamatan Katingan Tengah Kabupaten Katingan adalah adanya pembeli lain. Penjual berusaha menggunakan bahasa yang dapat dimengerti oleh pembelinya dalam hal ini penjual berusaha menyesuaikan dengan bahasa pembelinya. Fenomena alih kode yang dilakukan oleh penjual sering terjadi dalam melakukan transaksi jual beli.Berikut ini adalah percakapan yang menggambarkan peristiwa alih kode yang dilakukan penjual karena adanya calon pembeli lain.

a. Peserta tutur

Pedagang ayam: jenis kelamin perempuan, umur 45 tahun, etnis Banjar

Pembeli: (1): jenis kelamin perempuan, umur 42 tahun, etnis Katingan dan

Pembeli (2): jenis kelamin perempuan,umur 30 tahun, etnis Banjar.

b. Lokasi: Pasar Banjar Tumbang Samba Katingan Tengah

c. Topik : Tawar menawar ayam dan hati ayam

Pembeli : Pire rega manuk jikau? 1

Berapa harga ayam itu?

Penjual : Talung puluh ije kilo. 2 35 satu kilo

Pembeli : Dia tawa kurang. 3 Tidak bisa kurang?

Penjual : Dia tau am. Isut ih aku duan untung. 4 Tidak bisa lagi. Sedikit aku ambil untung

Datang calon pembeli lain (pembeli 2) yang menanyakan harga hati ayam.

Penjual : Handak ayamkah? 5 (BK-BB) Mau ayamkah?

Pembeli 2 : Barapa hati ayam? 6

Penjual : Hatikah, 2 lima ribu, handakkah? 7 Hati, 2 lima ribu, mau kah?

Pembeli 1 : Iyoh, aku mili ije kilo ih. 8 Iya, saya beli satu kilo saja.

Penjual : Penglaris nah 8 ( sambil menggerakkan uang tadi ke barang dagangannya supaya cepat laris).

Berdasarkan percakapan antara penjual, pembeli 1 dan pembeli 2, terjadi fenomena alih kode yang dilakukan oleh penjual. Pada awalnya penjual menggunakan Bahasa Katingan (BK) pada saat melayani pembeli 1 dan kemudian beralih menggunakan Bahasa Banjar (BB) pada saat menawarkan ayam pada pembeli 2 .

Penjual ayam yang beretnis Banjar ini menguasai bahasa Banjar dan bahasa Katingan. Jadi, tidak memiliki kendala untuk menyesuaikan dengan bahasa pembelinya. Pada saat calon pembeli (pembeli 2) lewat, penjual menggunakan bahasa Banjar untuk menawarkan ayamnya yang berbunyi “Handak ayamkah?” (penggalan kalimat 5) yang maknanya adalah 'Mau ayamkah?'. 


\section{Adanya Orang ketiga (03)}

Faktor yang mempengaruhi seseorang melakukan alih kode di Pasar Tumbang Samba Katingan Tengah adalah adanya orang ketiga. Orang ketiga yang dimaksud adalah seseorang yang juga ikut terlibat dalam percakapan. Peneliti menemukan penjual yang melakukan alih kode disebabkan menyesuaikan bahasa temannya yang sama-sama sebagai penjual.

Fenomena alih kode yang dilakukan oleh penjual dapat dilihat pada percakapan transaksi jual beli ubi di bawah ini.

\section{Peristiwa tutur 15}

a. Peserta tutur

Pedagang ubi

Pedagang sayur (03)

Pembeli

b. Lokasi

c. Topik

Pembeli

Penjual

Pembeli

Penjual

Pembeli
: jenis kelamin perempuan, umur 28 tahun, etnis Katingan

: jenis kelamin perempuan, umur 30 tahun, etnis Katingan

: jenis kelamin perempuan,umur 30 tahun, etnis Banjar

: Pasar Banjar Tumbang Samba Katingan Tengah

: Tawar menawar ubi

: Hapuklah gumbilinya ni? 1

Enaklah (renyah) ubi ini

: Nah, jar orang samalam hapuk pang. 2(BB)

Nah, kata orang kemarin enak.

: Barapa sakilo? 3

Berapa satu kilo?

: 4 ribu ja, banyak dah ditukari orang tadi. 4 (BB)

4 ribu.saja, sudah banyak dibeli orang tadi.

: Malihati dulu lah. 5

Melihat dulu lah.

Ketika pembeli memilih ubi, teman dari penjual ubi ini, yakni penjual sayur yang tempatnya berdekatan menanyakan apakah ada membeli beras. Percakapan antara penjual tersebut sebagai berikut.

Penjual (03)

: Indu Apri, tige ikau mili behas. 6

Ibu Apri, ada beli beras

Penjual

: Tige ih, aku mili ikan H. Utuh.7 (BB-BK)

Penjual (03)

Ada, aku beli di tempat $\mathrm{H}$. Utuh

Penjual

: Pire rega behas ikan H. Utuh te. 8

Berapa harga beras tempat $\mathrm{H}$. Utuh.

Pembeli

: Uju puluh ih ije sak a.

70 satu karung.

: Nah, timbangakan gumbilinya. 10

Penjual

Nah, timbangkan ubinya.

Pembeli

Penjual

: Pas akan akan satu kilo haja nah. 11(BK-BB)

Jadikan satu kilo saja.

: Tukarlah. 12 beli

: Jual jua. 13 jual juga

Wacana di atas telah memperlihatkan bahwa penjual melakukan alih kode karena menyesuaikan bahasa yang digunakan oleh lawan bicara. Pada awalnya pedagang sayur menggunakan bahasa Banjar pada saat melayani pembeli yang bertanya. Pada saat penjual menjawab pertanyaan dari calon pembelinya yang berbunyi "Nah, jar orang samalam hapuk pang" (penggalan kalimat 3) yang maknanya adalah 'Nah, kata orang kemarin enak'. Peristiwa alih kode 
Vol.3 No.1, 1 April 2018

terjadi pada saat penjual ubi menjawab pertanyaan dari temannya yang juga sama-sama pedagang. Pedagang sayur menanyakan kepada temannya yakni penjual ubi yang berbunyi " Indu Apri, tige ikau mili behas" (penggalan kalimat 6) yang maknanya adalah 'Ibu Apri, kamu ada beli beras'. Dari percakapan tersebut, penjual mulai beralih kode menggunakan bahasa Katingan untuk menjawab pertanyaan dari temannya tadi yang berbunyi “Tige ih, aku mili ikan H. Utuh" (penggalan kalimat 7) yang maknanya adalah 'Ada, aku beli di tempat H. Utuh'

\section{Pembeli Terkejut dengan Harga yang Ditawarkan}

Faktor yang juga mempengaruhi seseorang melakukan alih kode di Pasar Banjar Tumbang Samba Kecamatan Katingan Tengah Kabupaten Katingan adalah pembeli terkejut dengan harga yang ditawarkan oleh penjual. Pembeli tersebut secara spontan melakukan alih kode. Fenomena alih kode yang dilakukan oleh pembeli tersebut dapat dilihat pada percakapan transaksi jual beli ikan gabus di bawah ini.

a. Peserta tutur

Pedagang ikan gabus: jenis kelamin perempuan,umur 32 tahun, etnis Banjar

Pembeli: jenis kelamin perempuan, umur 37 tahun, etnis Katingan

b. Lokasi : Pasar Banjar Tumbang Samba

c. Topik : Tawar menawar ikan gabus

Penjual : Iwak haruan, iwak haruan. 1 (menawarkan ikan gabus kepada pembeli yang lewat) Ikan gabus, ikan gabus

Pembeli : Barapa sakilo? 2 (BB)

Berapa satu kilo?

Penjual : Duwe lime. 3 (25)

Pembeli : Akuy kalarang ampi nah, buhen tau larang kutuh. 4 (BB-BK) Aduh mahalnya, mengapa bisa mahal seperti ini.

Penjual : Jituh gin aku isut ih duan untung. 5 (BB-BK) Ini saja aku sedikit ambil untung.

Pembeli : Aku male mili lauk jikau duwe puluh ih ije kilo.6 Aku kemarin beli lauk itu 20 satu kilo.

Berdasarkan wacana di atas terlihat bahwa pembeli terkejut dengan harga ikan gabus yang bisa dikatakan cukup mahal dari harga biasanya. Keterkejutan pembeli tersebut menyebabkan dia melakukan alih kode. Pada awalnya, pembeli menyesuaikan bahasanya dengan penjual ikan gabus yakni berkomunikasi menggunakan bahasa Banjar yang berbunyi "Barapa sakilo" (penggalan kalimat 2) yang maknanya adalah 'Berapa satu kilo' setelah mendengarkan harga satu kilo ikan gabus, pembeli beralih menggunakan bahasa Katingan yang berbunyi "Akuy kalarang ampi nah, buhen tau larang kutuh" (penggalan kalimat 4) yang maknanya adalah 'Aduh mahalnya, mengapa bisa mahal seperti ini'. Dari percakapan pembeli tersebut terlihat peristiwa alih kode. Penjual yang pada awalnya menggunakan bahasa Banjar kemudian beralih kode menyesuaikan dengan bahasa pembeli. 


\section{Penjual Ingin Berpura-pura kepada Pembeli}

Penjual berpura-pura kepada pembeli juga dapat dijumpai dalam kegiatan transaksi jual beli di Pasar Banjar Tumbang Samba Kecamatan Katingan Tengah Kabupaten Katingan. Kepura-puraan tersebut membuat penjual melakukan alih kode. Berikut ini adalah percakapan yang menggambarkan peristiwa alih kode yang dilakukan oleh penjual kepada pembeli yang bersikap berpura-pura.

a. Peserta tutur

Pedagang sepatu: jenis kelamin laki-laki,umur 37 tahun, etnis Banjar

Pembeli: jenis kelamin perempuan, umur 23 tahun, etnis Katingan

b. Lokasi : Pasar Banjar Tumbang Samba Katingan Tengah

c. Topik : Tawar menawar sepatu

Pembeli $\quad$ : Pire rega sepatu jituh.1

Berapa harga sepatu ini.

Penjual : Jite uju puluh. 2

Itu 70.

Pembeli : Dia jahawen puluh ih kah, mangat aku mili jite. 3

Tidak 60 saja kah, supaya saya beli itu.

Penjual : Biar ih akam jahawen lime ih gin, jadi aku kurang ah te lime ribu. 4

Biar buat kamu 65, mengurangi 5 ribu.

Pembeli : Jahawen puluh ih, aku duan ji warna babilem. 5 60 saja saya ambil warna hitam.

Penjual : : Ayuja ambil, aku menjual ni gara-gara kasian dengan kam haja. Bila orang lain tadi, kada menjual aku. Warna apa tadi? 6

Dari wacana di atas, terlihat bahwa penjual beralih kode yang pada awalnya menggunakan bahasa Katingan dan kemudian menggunakan bahasa Banjar. Alih kode yang dilakukan oleh penjual menggunakan bahasa Katingan yang berbunyi "Biar ih akam jahawen lime ih gin, jadi aku kurang ah te lime ribu" (penggalan kalimat 4) yang maknanya adalah 'Biar buat kamu 65, mengurangi 5 ribu' ke dalam bahasa Banjar yang berbunyi “Ayuja ambil, aku menjual ni gara-gara kasian wan kam haja. Bila orang lain tadi ada menjual aku," (penggalan kalimat 6) yang maknanya adalah silakan ambil, saya menjual ni karena kasihan dengan kamu saja. Bila orang lain tadi tidak saya jual'. Dari tuturan penjual tadi tampak penjual berpura-pura kepada pembeli. Kepura-puraan tersebut terlihat dari penjual yang mengatakan ambil saja karena saya kasihan sama kamu, kalau orang lain saya tidak jual. Penjual berpura-pura kepada pembeli agar bisa dikatakan murah oleh pembeli. Sebenarnya, barang yang dijual sudah memiliki untung yang banyak. Penjual berusaha menarik minat pembeli, agar selalu berbelanja ke tokonya walaupun penjual tidak mengatakannya secara langsung.

\section{Perasaan Jengkel Penjual kepada Pembeli}

Faktor penentu yang menyebabkan seseorang melakukan alih bahasa adalah karena penjual merasa jengkel kepada pembeli. Hal ini juga ditemukan dalam proses transaksi jual beli di Pasar 
Banjar Kecamatan Katingan Tengah. Alih kode tersebut di lakukan oleh penjual yang beretnis Katingan dengan pembeli yang beretnis Jawa.

Peristiwa tutur 19

a. Peserta tutur

Pedagang ikan

Pembeli

b. Lokasi

c. Topik

Pembeli

Penjual

Pembeli

Penjual

Pembeli

Penjual

Pembeli
: jenis kelamin perempuan, umur 45 tahun, etnis Katingan

: jenis kelamin perempuan, umur 38 tahun, etnis Jawa

: Pasar Banjar Tumbang Samba

: Tawar menawar ikan

: Berapa satu bungkus seluang ini. 1

: 7 ribu satu bungkus. Mau kah? 2(BI)

: Kemarin 5 ribu satu bungkus. 5 saja saya ambil 2 bungkus. 3

: Dia tau, ije bungkus te isut ih duan untung. 4 (sambil mengelengkan kepala) (BI-BK)

Tidak bisa, satu bungkus itu sedikit saja mengambil untung.

: Tidak bisa kurang lagi ya? 5

: Ayu ih, duwe bungkus te 136.

Biar saja dua bungkus itu 13.

: Saya ambil yang ini. Minta plastiknya. 7

Dari percakapan di atas tampak penjual melakukan alih kode secara spontan kepada pembeli. Alih kode yang dilakukan karena penjual merasa jengkel kepada pembeli yang terlalu murah menawar harga ikan seluanga yang dijualnya. Penjual jengkel karena harga ikan pada saat itu bisa dikatakan mahal dan susah untuk mencari ikan. Dari percakapan antara penjual dan pembeli tersebut, komunikasi tidak mengalami hambatan walaupun penjual menggunakan bahasa Katingan, di antara kedua belah pihak saling mengerti apa yang dimaksudkannya. Pembeli yang beretnis Jawa ini mengerti dengan bahasa Katingan karena sudah sering mendengarkan di lingkungannya dengan menggunakan bahasa Katingan.

\section{Penjual Ingin Menekankan}

Faktor yang juga menyebabkan penjual dalam proses transaksi jual beli di Pasar Tumbang Samba Kecamatan Katingan Tengah melakukan alih kode adalah penjual ingin menekankan kepada pembeli. Alih kode tersebut terjadi pada penjual yang beretnis Jawa dan dan pembeli yang beretnis Banjar. Berikut ini adalah percakapan yang menggambarkan penjual melakukan alih kode kepada pembeli pada saat tawar menawar seragam SD.

a. Peserta tutur

Pedagang kain : jenis kelamin laki-laki, umur 37 tahun, etnis Jawa

Pembeli : jenis kelamin perempuan, umur 32, etnis Banjar

b. Lokasi

c. Topik

: Pasar Banjar Tumbang Samba

Pembeli

: Tawar menawar baju

: Ada bajual baju seragam SD lah? 1

Ada jual baju seragam SD? 


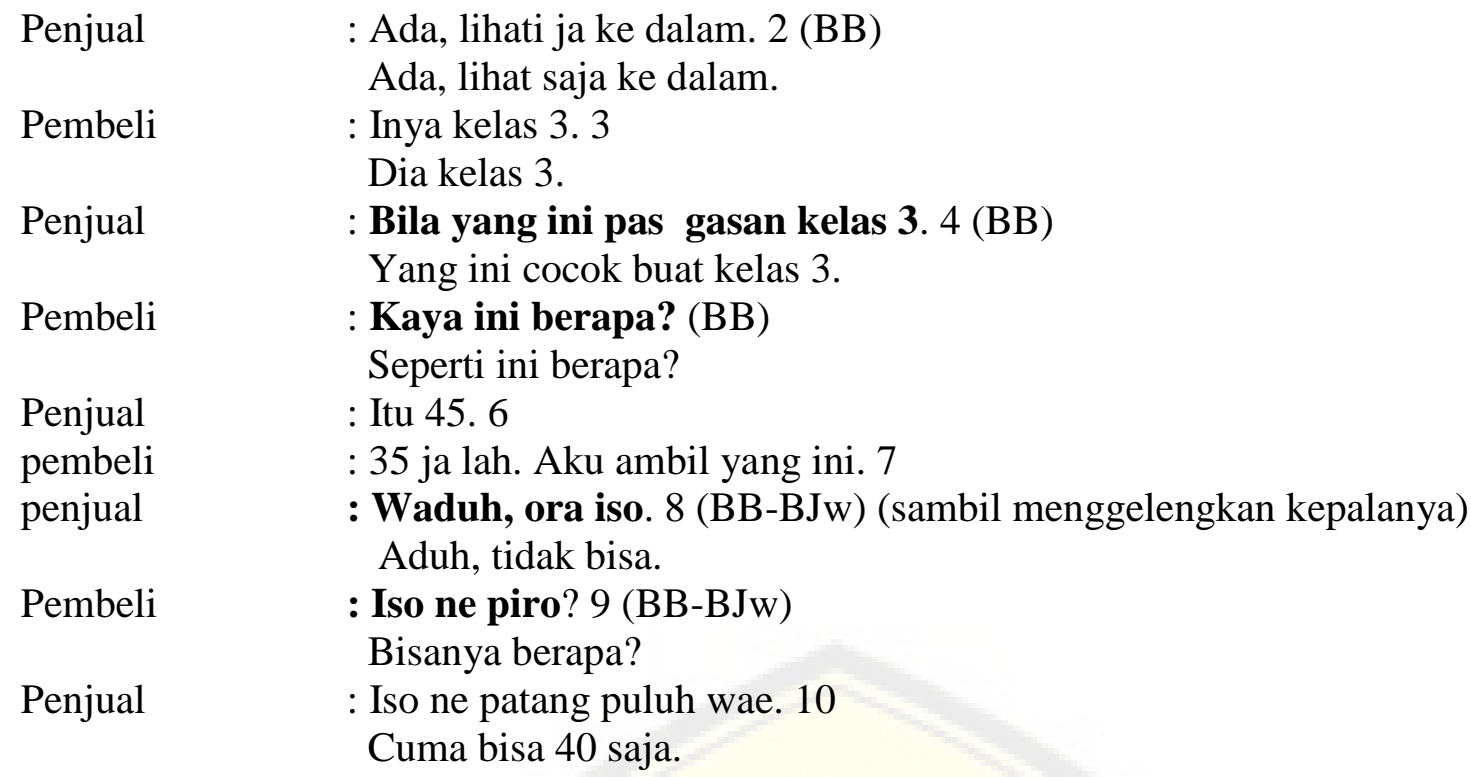

Percakapan antara penjual dan pembeli tersebut menggambarkan fenomena alih kode yang dilakukan oleh penjual. Pada awalnya, penjual menggunakan bahasa Banjar menyesuaikan dengan bahasa pembeli yang berbunyi "Bila yang ini pas gasan kelas 3" yang maknanya adalah 'Yang ini cocok buat kelas 3' (penggalan 4) kemudian penjual beralih kode menggunakan bahasa Jawa yang berbunyi "Waduh, ora iso" (penggalan kalimat 8) yang maknanya adalah 'Aduh, tidak bisa'. Ada hal yang ingin ditekankan oleh penjual dengan harga seragam SD tersebut. Penjual berusaha menegaskan kepada pembeli bahwa tidak bisa menjual dengan harga yang diingikan pembeli, yakni 35 dengan berbahasa Jawa. Ketika penjual beralih menggunakan bahasa Jawa, pembeli yang beretnis Banjar berusaha mengimbangi bahasa yang digunakan oleh penjual walaupun pembeli hanya sedikit menguasai bahasa Jawa.

\section{Simpulan}

Beragamnya bahasa yang digunakan dalam dalam proses transaksi jual beli di Pasar Banjar Kecamatan Katingan Kabupaten Katingan ini, sehingga menimbulkan terjadinya peralihan bahasa atau alih kode. Kode bahasa yang digunakan oleh masyarakat untuk berkomunikasi adalah BK, BI, BB, dan BJw. Keempat kode bahasa tersebut digunakan oleh masyarakat di Kecamatan Katingan Tengah pada saat proses transaksi jual beli di Pasar. Peristiwa alih kode yang dilakukan baik penjual maupun pembeli tersebut memiliki sebab. Dalam melakukan kegiatan transaksi jual beli di Pasar Banjar terdapat beberapa faktor penentuterjadinyaalihkode, yakni 1) pembeli dan penjual sudah saling kenal, 2) menyesuaikan dengan bahasa pembeli, 3) agar mendapatkan harga murah, 4) adanya orang ketiga, 5) adanya pembeli lain, 6) pembeli terkejut dengan harga yang ditawarkan, penjual ingin berpura-pura kepada pembeli, 7) perasaan jengkel penjual kepada pembeli, dan 8) penjual ingin menekankan. 


\section{Daftar Pustaka}

Adul, Asfandi. 1984. Sikap Bahasa: Perilaku Manusia dalam Berbahasa. Banjarmasin: Universitas Lambung Mangkurat

Alwasilah, A. Chaedar. 1993. Pengantar Sosiologi Bahasa. Bandung: Angkasa Bandung.

Anwar, Khaidir. 1990. Fungsi dan Peranan Bahasa, Sebuah Pengantar. Yogyakarta: Gadjah Mada University Press.

Arifin, E. Zaenal, dan S. Amran Tasai. 2008. Cermat Berbahasa Indonesia untuk Perguruan Tinggi. Edisi Revisi. Jakarta: Akademika Pressindo.

Arikunto, Suharsimi. 2010. Prosedur Penelitian suatu pendekatan Praktik. Jakarta. Rineka Cipta

Chaer, Abdul, 2003. Linguistik Umum. Jakarta: Rineka Cipta.

Chaer, Abdul dan Leonie Agustina. 2004. Sosiolinguistik, Perkenalan Awal. Cetakan kedua. Jakarta: PT Rineka Cipta.

Djajasudarma, T. Fatimah dan Wilson Nadeak (Eds.). 1996. Bahasa dan Sastra Indonesia: Seminar HPBI Bandung. Bandung: HPBI dan Yayasan Pustaka Wina.

Hapip, Abdul Djebar. 2008. Kamus Banjar Indonesia. Banjarmasin: CV. Rahmat Hafiz Al Mubaraq.

Kesuma, Tri Mastoyo Jati. 2007. Pengantar (Metode) Penelitian Bahasa. Yogyakarta: Corasvatibooks.

Kridalaksana, Harimurti. 1985. Fungsi Bahasa dan Sikap Bahasa. Nusa Indah.

---. 2001. Kamus Linguistik. Edisi Ketiga. Jakarta: PT Gramedia Pustaka Utama

---. 2009. Sosiolinguistik.Kajian Multidisipliner. Malang: Universitas Negeri Malang.

---. 2010. Dasar-Dasar Sosiolinguistik. Jogjakarta: Pustaka Prisma.

Rahardi, R. Kunjana. 2001. Sosiolinguistik, Kode, dan Alih Kode. Yogyakarta: Pustaka Pelajar. 